\title{
Os lugares dos historiadores e da história na sociedade brasileira: Conferência de abertura do XXVIII Simpósio Nacional de História, Florianópolis
}

The places of historians and history in Brazilian society: Opening Conference of the XXVIII National Symposium on History, Florianópolis

\section{Rodrigo Patto Sá Motta}

rodrigopsamotta@gmail.com

Professor adjunto

Universidade Federal de Minas Gerais

Faculdade de Filosofia e Ciências Humanas

Av. Presidente Antônio Carlos, 6627, $4^{\circ}$ andar, sala 4134

31270-901 - Belo Horizonte - Minas Gerais

Brasil

Palavras-chave

História do tempo presente; Historiografia brasileira; História da historiografia.

Keywords

History of present time; Brazilian historiography; History of Historiography. 
Gostaria de iniciar esta conferência dizendo da grande honra que é estar à frente da nossa entidade - e de vocês - e fazer a conferência inaugural do Simpósio Nacional dos historiadores brasileiros. Essa sensação fica ainda mais intensa quando trazemos à memória as inúmeras pessoas que trabalharam pela ANPUH durante as suas cinco décadas de existência, responsáveis por construir essa bela história. Exatamente por perceber a dimensão da responsabilidade assumida é que esta diretoria trabalhou muito ao longo do biênio que se encerra agora, para administrar condignamente e mesmo aprimorar o legado recebido dos nossos antecessores.

É com grande felicidade que vivenciamos este momento de abertura do XXVIII SNH, um evento muito ansiado e muito importante para nossa área, e que exigiu o trabalho dedicado de inúmeras pessoas. Difícil expressar o reconhecimento devido a todas e a todos que trabalharam pelo sucesso do SNH, em especial os colegas da ANPUH/SC, da UFSC e da UDESC. O sucesso deste evento deve muito à dedicação abnegada das(os) colegas de SC, e, especialmente, ao seu profissionalismo e capacidade de trabalho em equipe. A diretoria que tenho o prazer de dirigir, e que igualmente se empenhou a fundo para garantir um excelente Encontro, teve sorte de contar com parceiras e parceiros assim para compartilhar a organização do SNH 2015.

Este evento foi organizado em torno de um tema que serve de mote e inspira à reflexão: os lugares dos historiadores, velhos e novos desafios. Há diversas maneiras de interpretar e de dialogar com esse tema, e algumas delas

322 implicam questões cruciais para todos nós, tanto os profissionais da história como a sociedade.

O primeiro lugar dos historiadores que gostaria de mencionar está exatamente aqui, a ANPUH. Comecemos refletindo sobre o lugar que a ANPUH ocupa, e os espaços que ela poderia ocupar. É fundamental fortalecer ainda mais nossa entidade, que já é uma senhora madura a caminho de completar 54 anos de vida. Afinal, ela ocupa um lugar indispensável para os(as) historiadores(as), já que nos oferece espaço para reunião e debate, e nos representa como grupo profissional.

Reside aí, exatamente, um grande desafio: combinar de maneira adequada o papel da ANPUH como entidade representativa dos historiadores, portanto o seu lugar político, com a sua faceta de entidade acadêmica, ambos igualmente importantes. Segundo alguns registros de memória, desde o seu primeiro evento a ANPUH enfrenta esse dilema. Falso dilema, assim me parece, pois a entidade deve cuidar das duas frentes de ação. O verdadeiro desafio é encontrar o adequado equilíbrio entre as duas facetas. Além de representar os interesses comuns dos historiadores, o que passa frequentemente por uma discussão prévia - às vezes uma disputa - para definir tais interesses, a ANPUH deve fortalecer sua dimensão de entidade científica, o seu papel de fomentar o debate e a produção do conhecimento na área de história, como temos feito por meio das Jornadas da ANPUH, por exemplo. Na mesma linha, é muito importante que a entidade trabalhe para elevar ainda mais a qualidade do debate acadêmico promovido nos seus eventos. 
Não é fácil manter em equilíbrio esses dois lados da entidade, o lado político e o lado científico, pois existem pressões e estímulos conjunturais que podem levar a balança a pender para uma das direções. É fundamental não deixar esmaecer a faceta acadêmica da ANPUH, pois quanto mais respeitável ela for do ponto de vista acadêmico, quanto mais for reconhecida pela linha de frente da historiografia, e também pelas demais entidades científicas, tanto mais força terá para exercer a função de representar os historiadores. E tanto maior será sua capacidade de ocupar um lugar político relevante, um aspecto da atuação da ANPUH (e dos historiadores) fundamental, e que será retomado adiante.

Refletir sobre o papel da ANPUH como entidade científica tornou-se ainda mais importante no quadro recente, em vista da criação de novas organizações associativas dedicadas a campos específicos do conhecimento histórico. É sinal de pujança da área, sem dúvida, a indicar o desenvolvimento e consolidação de grupos de pesquisa que sentem necessidade de criar espaços próprios de discussão. Esse processo denota o crescimento do nosso campo e, portanto, deve ser considerado positivo. E é assim que penso, sinceramente, não vejo as novas entidades como concorrentes da ANPUH, e nem que elas tenham tal intenção. Um sinal positivo nessa direção é a participação de dirigentes de algumas dessas entidades nas atividades da ANPUH, da qual são sócios e à qual reconhecem como a entidade maior dos historiadores do Brasil.

Esclarecendo o argumento, a preocupação é encontrar uma forma de compatibilizar a diversificação da área com o fortalecimento da ANPUH como espaço de debate acadêmico para os historiadores. Trata-se de questão para refletir com calma, mas uma alternativa seria pensar novas formas de organizar a relação entre a ANPUH e os grupos de pesquisa, especialmente os GTs, que já são parte da nossa estrutura, mas também pensar outras maneiras de integrar as entidades científicas. Seja como for, reitero o ponto principal: precisamos aumentar ainda mais a densidade acadêmica da nossa entidade, o que incrementará a sua capacidade de representação, inclusive do ponto de vista político.

Do que foi dito não se deve depreender sintoma de fraqueza, bem ao contrário. A ideia é planejar o futuro e adaptar a entidade para novos desafios que virão logo à frente. Na verdade, a ANPUH está bastante forte, notadamente no que toca ao quadro de associados, que atingiu números impressionantes. No momento, temos 7.224 associados, sendo que penas neste ano de 2015 foram 1.422 novas filiações.

Outro sinal de pujança da ANPUH, claro, é este Simpósio Nacional de História, que tem números marcantes: mais de 3 mil comunicações (distribuídas em cerca de 110 Simpósios Temáticos), mais de 20 Grupos de Trabalho em funcionamento, dezenas de minicursos e oficinas, lançamento de 136 publicações durante o evento, e um público estimado total de 5 mil e 500 pessoas.

Com o crescimento, previsivelmente, aumentaram as demandas e os problemas que somos instados a enfrentar. Por isso, outro grande desafio é melhorar a infraestrutura da nossa entidade, para oferecer à diretoria e aos colaboradores condições de atender adequadamente às demandas que chegam à 
ANPUH todas as semanas. Nossa infraestrutura melhorou de maneira significativa nos últimos anos, graças ao excelente trabalho de sucessivas diretorias, mas, ainda é insuficiente diante das demandas crescentes.

A expansão do nosso quadro associativo em anos recentes deveu-se também ao crescimento do sistema universitário e de pós-graduação no mesmo período. Infelizmente vivemos um momento ruim este ano, com corte de verbas e retração de investimentos públicos. A propósito, há algumas semanas fizemos um manifesto protestando contra o corte de verbas federais para os cursos de pós-graduação. Esperamos que a maré ruim passe e as coisas melhorem a partir de 2016.

De qualquer modo, o crescimento da fase anterior foi enorme e gerou o grande sistema universitário que temos hoje. Para percebê-lo basta citar alguns dados estatísticos. Segundo dados do INEP, havia em 2013 no Brasil 514 cursos de licenciatura em História (presenciais e EAD), com 79,3 mil alunos, dos quais um pouco mais de 11 mil obtiveram a graduação naquele ano. E mais 68 cursos de história (presumivelmente bacharelado), com cerca de 8,4 mil alunos (com 1.290 concluintes). Assim, em 2013 havia quase 90 mil pessoas fazendo graduação em história no Brasil, e é provável que o número hoje seja ligeiramente mais elevado.

Os dados mostram que os cursos de graduação formam cerca de 10 mil historiadores por ano. Mesmo que apenas uma parte deles entre no mercado de trabalho exercendo a nossa profissão, está claro que temos um campo enorme 324 para ampliar a atuação da ANPUH. O mesmo pode ser dito quando observamos os dados para a pós-graduação, em que o crescimento foi ainda mais intenso.

Na pós-graduação stricto sensu, de acordo com a página da CAPES, temos hoje 69 programas na área de história, dos quais 9 são mestrados profissionais, 23 são mestrados acadêmicos e 37 oferecem simultaneamente mestrado e doutorado. Em 2012, que o foi último ano considerado na avaliação mais recente da CAPES, havia 2039 doutorandos e 3555 alunos fazendo mestrado, números que vêm crescendo continuamente. No mesmo ano de 2012, foram defendidas 929 dissertações de mestrado e 287 teses de doutorado na área de história que, junto à produção dos historiadores mais experientes, confluem para a publicação de centenas de artigos, capítulos de livro e livros autorais.

São dados alvissareiros, não há dúvida, que indicam a enorme pujança da nossa área e do sistema universitário brasileiro como um todo. Evidentemente, nossa situação relativa no quadro internacional mudou para melhor - embora necessitemos ainda melhores estratégias para a chamada internacionalização - e o horizonte parece promissor, desde que a crise econômica e os cortes no financiamento público sejam, efetivamente, conjunturais.

Os dados sobre a pós-graduação colocam em foco mais um lugar fundamental para os historiadores, o da produção do saber. Nesse domínio, um dos desafios é combinar o aumento quantitativo da produção com a devida qualidade. Isso evitaria distorções e mesmo certos exageros, que de tão disseminados afetam até estudantes nos semestres iniciais da graduação, alguns já obcecados em rechear o "Lattes", independente da qualidade dos 
produtos. Autoridades responsáveis estão cientes e existem algumas iniciativas positivas, mas há muito o que discutir e aperfeiçoar, inclusive nos processos avaliativos, que têm falhas e nem sempre são acompanhados da necessária transparência. A avaliação é fundamental para aferir a qualidade da produção do conhecimento, assim como para balizar o bom uso dos recursos públicos. E não devemos aceitar críticas vagas contra o quantitativismo que servem apenas para escamotear falta de compromisso e incompetência. No entanto, para que cumpra seus objetivos, a avaliação deve priorizar a qualidade, e não empurrar todo o sistema educacional e de pesquisa na direção de uma corrida sem fim pelo incremento de estatísticas.

Um ponto importante é persistir na luta para que as agências responsáveis pela avaliação reconheçam o livro como resultado principal da produção dos historiadores, e de outros pesquisadores afins. O livro autoral demanda tempo para maturar, o que está em contradição com a noção de urgência de certa lógica burocrática. Claro que os artigos publicados em periódicos são meios significativos de divulgar a produção, no entanto, os livros autorais têm impacto mais importante na nossa área. Os livros autorais resultam de investigações e análises acumuladas em período de tempo dilatado e têm formato adequado à produção e divulgação de conhecimento inovador no campo da história, já que colocam em foco objetos complexos cujo escopo não é compatível com a forma artigo. Por isso, é fundamental defender as características próprias à nossa disciplina (e à área de Humanas como um todo) e não se dobrar aos padrões das ciências naturais que, devido às suas especificidades, produzem prioritariamente artigos.

Gostaria de destacar agora outro lugar em que se faz fundamental a presença e a atuação dos historiadores e das historiadoras: o espaço público. Ressalte-se que a expressão está sendo usada em sentido lato, para evitar um debate conceitual que não cabe neste momento. Refiro-me aos espaços e locais de circulação de ideias e opiniões, em especial as mídias tradicionais e as novas redes sociais, mas também as escolas, as universidades e outras esferas de sociabilidade.

É fundamental termos estratégias corretas e, antes de tudo, a disposição para enfrentar e ocupar esses espaços. Nesse lugar, frequentemente nos vemos diante de um dilema, pois a pesquisa e a produção de conhecimento na área de história demandam muito tempo, como já ressaltado. Por isso, não é fácil encontrar energia para atuar nos espaços públicos. Além do mais, encontramos muitos aborrecimentos nesse caminho e, por vezes, frustração. Ainda assim, é preciso ter disposição para enfrentar as intempéries, e riscos, tanto por dever profissional quanto por obrigação cívica.

Nesse campo está incluído o desafio da divulgação do conhecimento, um problema chave para todas as áreas do saber, posto que não é suficiente realizar uma produção de boa qualidade. Necessário também que essa produção seja divulgada, tanto para o grande público como, na nossa situação, para o sistema escolar. No último caso, não se trata de pensar uma relação hierárquica e unidirecional. As escolas não são consumidoras passivas da produção 
universitária, além do que os profissionais do ensino básico têm a sua própria produção. Ainda assim, permanece verdade que pesquisas realizadas na ponta da historiografia influenciam a produção nas escolas.

Porém, gostaria de destacar o desafio da divulgação mais ampla do conhecimento histórico, para além do espaço escolar. Para isso, há que considerar o quadro em que vivemos, marcado por notável curiosidade pública em relação a representações sobre o passado, tanto as que são produzidas pela história como as que são produzidas por outras formas de discurso. Muitas pessoas desejam consumir representações sobre o passado, mas, com frequência, esse público contenta-se com versões superficiais e/ou pitorescas sobre personagens e eventos históricos. Esse fenômeno há muito tornou-se um nicho no mercado editorial e cultural, e não tem faltado oferta de produtos para atender a essa demanda, por vezes com resultados muito lucrativos. Há cerca de um século falava-se, em geral de maneira crítica, da existência de uma literatura "sorriso da sociedade". Pois bem, hoje temos também um gênero de história "sorriso da sociedade", mais preocupada em entreter do que em analisar e refletir. Não se trata de fazer uma crítica moralista do fenômeno, nem meramente de saber quem vai ganhar o mercado, se os historiadores ou outros profissionais. A preocupação é alertar para a necessidade de ocupar esses espaços, especialmente para que a oferta ao grande público inclua também produtos de boa qualidade.

A propósito, vale a pena lembrar a distinção clássica entre o conhecimento histórico e outras formas de representar o passado ou a experiência no tempo. 326 A distinção está no fato da história operar com procedimentos científicos, seguir um método, pautar-se pela crítica das fontes e buscar evidências diversificadas. O historiador deve desconfiar das suas fontes, inquiri-las em busca da verdade, uma meta que é inalcançável em sentido puro, mas que ainda assim permanece o objetivo principal. Portanto, o ponto diferencial é que o historiador pode levar ao público um conhecimento mais crítico, mais reflexivo. Nós também podemos atender à curiosidade e à necessidade de divertimento do grande público, mas, com a peculiaridade de incluir no pacote o "biscoito fino", ou seja, levar o leitor à reflexão crítica.

Por esse roteiro chegamos ao lugar político da história. Eis aí uma questão essencial: a política e o político estão inextricavelmente implicados na nossa disciplina. É impossível desconectar o conhecimento histórico da política, afinal, o nosso campo de saber nasceu no calor das disputas políticas e fortemente ligado ao Estado, que sempre se ocupou dos discursos e representações sobre o passado, invariavelmente tentando controla-los. Em séculos recentes, ou melhor, em décadas recentes, felizmente alcançamos condições de produção do conhecimento em clima de liberdade, inclusive com a possibilidade de criticarmos o Estado - e como criticamos! Mas, isso não significou uma redução do lugar político ocupado pela história. Ao contrário, o nosso campo continua tão imerso nas disputas políticas como sempre esteve. A diferença é que hoje há mais espaço para divergências e controvérsias, mais liberdade.

Diferentes projetos políticos recorrem à história para posicionar-se diante da sociedade e para buscar legitimidade, e não faltam exemplos para confirmar 
essa asserção. Naturalmente, é mais simples mencionar temas próximos a meu universo de pesquisa, como a questão das políticas de memória e de busca da verdade no que se refere às ditaduras recentes.

Naturalmente, um exemplo significativo são as chamadas Comissões da Verdade, cujas atividades envolveram historiadores dos dois lados, tanto no interior delas (no papel de pesquisadores ou assessores) como fora, nesse caso criticando os seus resultados ambíguos. Outro exemplo, mais próximo ainda, são os recentes protestos de rua (e nas redes sociais) contra o governo Dilma Rousseff, em que grupos políticos de direita apropriam-se do golpe de 1964 e da ditadura em chave positiva, defendendo que uma nova intervenção militar seria necessária e justa para salvar o país de novo do comunismo, e para entrega-lo mais uma vez aos homens de verde-e-oliva, que, de acordo com tal perspectiva, teriam feito um ótimo trabalho durante aqueles vinte anos de ditadura.

Portanto, mesmo que por hipótese desejássemos uma assepsia política da história, ou o afastamento da história em relação às lides políticas, isso seria impossível. Afinal, a história (e a memória) integra as estruturas mais básicas da constituição política das nossas sociedades, ao fornecer representações formadoras de imaginários coletivos que ajudam a instituir e dar legitimidade à comunidade política.

Brinquei há pouco com a hipótese de afastar a história das lides políticas. Mera brincadeira! Ao contrário, acho necessário o engajamento político dos historiadores. Evidentemente, estou pensando para além da mobilização em benefício dos nossos interesses como grupo, o que devemos fazer também e fazemos (como no caso do PL que regulamenta a nossa profissão, que não será tratado agora por ser tema da Assembleia de quinta-feira; pelos resultados positivos alcançados, ou seja, a virtual aprovação do projeto no Congresso, trata-se de exemplo de que podemos nos engajar de maneira eficiente em defesa de nossos interesses).

Refiro-me, em especial, ao engajamento em debates políticos mais amplos, de alcance social geral. Como a história integra necessariamente as disputas políticas, os historiadores são constantemente chamados a tomar parte do debate. E não deveriam se furtar a esse papel, que ao mesmo tempo provoca o dever profissional e toca a nossa obrigação cívica. O conhecimento histórico é importante elemento na formação da opinião política das pessoas e, nesse ponto, temos muito a oferecer.

A propósito, no Brasil há indicadores preocupantes sobre a existência de um conhecimento histórico e mesmo de uma cultura histórica precários na sociedade. Vou citar alguns resultados de pesquisa de opinião que ajudei a realizar em 2010, junto com meu colega Adriano Cerqueira. A enquete foi aplicada somente em quatro estados brasileiros (DF, MG, PE, PB), mas ainda assim pode ser considerada representativa.

A pesquisa teve muitas variantes, mas vou citar apenas o resultado para a primeira pergunta, uma questão aberta aplicada aos entrevistados: "O que aconteceu na política brasileira em 1964?" O índice de desconhecimento revelado nas respostas foi surpreendente, bem mais alto do que esperávamos. 
Nos quatro estados, somente entre $10 \%$ e $20 \%$ dos pesquisados conseguiram dar resposta satisfatória à pergunta, mencionando golpe, revolução ou ditadura (vocábulos que revelam, é claro, opiniões políticas diferentes em relação ao evento). Depois da primeira pergunta, e na medida em que a pesquisa avançou explorando outros temas, como a censura, o milagre econômico ou o tricampeonato de 1970, o índice de desconhecimento foi diminuindo. Mesmo assim, os resultados mantiveram elevado índice de desconhecimento total sobre a história da ditadura: mais de $60 \%$ dos entrevistados nessa pesquisa não tinha memória nem conhecimento sobre o crucial período vivido pelo país entre 1964 e 1984.

Frente a esses dados, cabe indagar: é possível ser cidadão com opinião política consistente na ausência de conhecimento sobre a história política recente do país? Como fazer escolhas entre os diferentes caminhos e propostas que se apresentam para o futuro? Como os cidadãos que desconhecem os eventos de 1964 e subsequentes podem se posicionar diante dos defensores de novo golpe político? Como podem avaliar a extensão e o significado da crise política e econômica atual, que alguns discursos procuram pintar em dimensões catastróficas, se desconhecem momentos anteriores que poderiam servir como balizas para análise?

Vale a pena insistir sobre a manipulação em torno de 1964, pois muitos atores estão formando a opinião de certos grupos com base em representações ligeiras sobre a ditadura. Parece-me que aqui é fundamental a nossa atuação.

328 Eis aí, portanto, um lugar chave para o historiador: o espaço público, o debate político, de que somos partes integrantes, inexoravelmente. A questão é perceber isso de maneira adequada e estabelecer a melhor forma de participar, de engajar-se, o que implica considerar a existência de limites.

A reflexão sobre os contornos e os limites do engajamento público nos leva a dois temas chave: os procedimentos éticos e a busca da verdade. (A questão da ética, a propósito, será discutida na Assembleia do dia 30). O engajamento público referido - e defendido - aqui deve ser balizado por princípios éticos. Não cabe ao historiador profissional, no exercício do seu trabalho, seja ele pesquisador ou professor, manipular o seu conhecimento para induzir as pessoas na direção de posições sectárias. É um equívoco essa forma de politizar o conhecimento histórico, pois, além de empobrecer a história, presta-se mal serviço político.

O assunto está mais candente nos dias atuais, pois existe uma iniciativa legislativa de inspiração direitista no Congresso para limitar o debate político nas salas de aula. Uma iniciativa infeliz que a ANPUH criticou em manifesto público, posto que a malsinada lei traria limites à liberdade dos professores em sala de aula e abafaria o debate político nas escolas. Ao contrário, necessitamos de mais debate político, precisamos de maior participação dos cidadãos para que formem opinião sólida no caminho que desejarem.

O argumento é que o historiador deve contribuir com o debate político, mas sem tentar empurrar qualquer pacote sectário de ideias. Devemos participar oferecendo bom conhecimento sobre a história, para que os cidadãos possam dele se apropriar e formar sua opinião política, suas próprias escolhas. Isso não 
significa dizer que devemos esconder nossa própria opinião, até porque isso é quase impossível na prática; mas significa defender um discurso pluralista, que respeita as diferenças. O pluralismo em questão deve ser bem entendido, pois há limites estabelecidos pelas convenções políticas dominantes e aceitas pela maioria (presumivelmente), e que estão consagrados na legislação. Trocando em miúdos, a aceitação do pluralismo não inclui compactuar com preconceitos e diferentes formas de opressão, como o racismo, a violência contra as mulheres, a homofobia, a intolerância religiosa entre outros, que devem ser denunciados e combatidos. De igual forma, e isso é uma preocupação atual, devemos ter tolerância zero para os discursos autoritários que defendem o retorno à ditadura, sob qualquer pretexto.

As temáticas do engajamento, da ética e do pluralismo (bem entendido, ou bem orientado como tentei argumentar) implicam outra questão fundamental, que é quase tabu em certos meios acadêmicos: a verdade.

Nos dias que correm, a questão da verdade não é debate restrito ao universo acadêmico, com repercussão somente nas polêmicas sobre os limites do conhecimento. Neste momento, em que estão em disputa representações sobre o passado recente de autoritarismo e violência, a demanda por verdade implica também desafios de ordem política e jurídica. Quando entram no foco da história os regimes autoritário-repressivos e, pensando de maneira mais ampla, qualquer forma de violência e opressão, os argumentos relativistas e hipercéticos, que são populares em alguns meios acadêmicos, revelam melhor as suas limitações. O investigador que atua nesse terreno não pode adotar o argumento relativista, ou seja, a posição de que discursos com pretensão à verdade devem ser desprezados como puro resquício do positivismo. A realidade é apenas um texto? Ela não passa de uma construção do historiador? Dá para aceitar tais postulados quando tratamos de temas como golpe de Estado, tortura, violência, trabalho escravo e censura? Não pode haver mesmo representações verdadeiras acerca da história?

É possível, sim, estabelecer certas verdades com base em evidências documentais. E não apenas no campo da história recente, é claro. Podemos afirmar, por exemplo, o fato de que houve um golpe autoritário em 1964, o fato de que a escravidão deixou um legado ainda não superado no Brasil, o fato de que o nazismo provocou o genocídio de judeus e ciganos europeus. A possibilidade de estabelecer asserções verídicas desse tipo implica, também, e isso é fundamental, a certeza de poder refutar certas inverdades e mistificações históricas.

Entretanto, para além do estabelecimento de verdades factuais, por fundamentais que elas sejam, a busca por explicações ou pela construção de sentidos implica desafios mais complexos, naturalmente, sujeitos a maiores polêmicas. Mesmo assim, tais polêmicas podem ser travadas em terreno firme, em que os referentes estejam bem estabelecidos, o que torna certas análises mais aceitáveis ou densas que outras. Em outras palavras: nem todas as interpretações sobre o passado têm o mesmo valor, o que nos permite reclamar um realismo crítico, distante tanto do positivismo quanto do relativismo cético, ambos igualmente ingênuos. Citando Paul Ricoeur: "Em outros termos, quando 
juntas, escrituralidade, explicação compreensiva e prova documental são suscetíveis de credenciar a pretensão à verdade do discurso histórico".

Assim, os historiadores podem e devem ter uma pretensão à verdade, sabendo dos limites e dificuldades implicados nesta busca, e o caráter provisório e incompleto do conhecimento que produzem. Precisamos estar atentos para o fato de que, alheios às disputas acadêmicas acerca das dificuldades para a construção de representações verdadeiras, outros agentes sociais interessados no passado recente almejam verdades inquestionáveis e absolutas.

Importante refletir sobre esse problema, também, tendo em vista a sua repercussão nos espaços de divulgação pública e de formação escolar. Considerando, em especial, o caso do ensino básico, o impacto do relativismo gera confusão e insegurança em relação ao valor do conhecimento histórico, além de disseminar a compreensão equivocada de que qualquer versão histórica tem igual valor.

A propósito, eis aí mais um lugar fundamental para a história e os historiadores: o ensino. O tema ficou para o final não porque seja menos importante que os outros, ao contrário. Voltemos nossa atenção agora para a educação básica, em especial o ensino fundamental e o médio, um lugar estratégico, sem dúvida. Do ponto de vista da nossa profissão, o lugar ocupado pela história e pelos historiadores na educação básica é absolutamente fundamental, pois ele vai definir, em grande medida, as linhas mestras da formação e da atuação profissional. O lugar ocupado pela história no ensino 3.30 escolar tem grande influência sobre o perfil da formação de historiadores nas universidades, tanto no que diz respeito aos números, ou seja, à quantidade de postos de trabalho, portanto às vagas necessárias no ensino superior, como no que se refere ao tipo de formação a ser enfatizado. Assim, o ensino básico define contornos essenciais da nossa profissão, e apenas por essa razão já deveria merecer a mais cuidadosa atenção.

No momento está em curso um debate decisivo, pois algumas lideranças políticas e autoridades educacionais têm se ocupado de mais uma reformulação do ensino básico. Um dos vértices dessa discussão é o projeto de lei 6.840, apresentado em 2013, que resultou dos trabalhos de uma comissão especial instituída pela Câmara dos Deputados (Comissão Especial destinada a promover Estudos e Proposições para o Ensino Médio - CEENSI) para reformular a Lei de Diretrizes e Bases da Educação no referente ao ensino médio. O Projeto de Lei incluiu algumas propostas excelentes, como o estabelecimento de jornada integral para os estudantes do nível médio, que teriam 7 horas diárias de ensino, além de outros pontos que não é possível comentar agora. Mas ele trouxe também alguns problemas.

Interessa destacar que o PL propõe reorganizar os currículos do ensino médio a partir de quatro áreas do conhecimento, a saber: linguagens, matemática, ciências da natureza e ciências humanas. Ademais, nota-se a intenção de estimular a integração entre as áreas partindo de certa noção vaga de interdisciplinaridade, com impactos importantes na formação de professores para o ensino básico que, no lugar de frequentarem cursos nas tradicionais áreas 
(história, geografia etc.) fariam, no nosso caso, uma licenciatura em Ciências Humanas. Essa tendência tem defensores tanto no poder Legislativo como no Executivo, já que há algum tempo o MEC tem estimulado a criação de cursos de licenciatura interdisciplinares, ideia bem acolhida em algumas universidades.

Para aumentar a nossa ansiedade, o projeto de lei dos deputados, em sua versão original, definia que "a base nacional comum dos currículos do ensino médio compreenderá, entre seus componentes e conteúdos obrigatórios, o estudo da língua portuguesa; da matemática; do conhecimento do mundo físico e natural; da Filosofia e da Sociologia; da realidade social e política, especialmente do Brasil; e uma língua estrangeira moderna". Pelo que se vê no texto, o PL poderia provocar o deslocamento da história e da geografia em benefício da Filosofia e da Sociologia, campos de saber muito próximos de nós, quase irmãos, mas que poderíamos começar a olhar como concorrentes caso a lei prosperasse em sua formulação original.

Da mesma forma que outras entidades, a ANPUH protestou contra o risco de desvalorização do conhecimento específico das disciplinas básicas implícito no projeto de lei. Não se trata de questionar a importância da interdisciplinaridade, mas de afirmar que essa só pode existir com base nas disciplinas, ou seja, se as disciplinas forem desestruturadas não poderá haverá interdisciplinaridade. Além disso, permanece a desconfiança de que o objetivo real da burocracia educacional é encontrar meios de lidar com a falta de professores para o ensino básico. Se essa interpretação (um pouco maliciosa, eu admito) estiver correta, a intenção seria, no lugar de enfrentar a razão principal para a falta de professores, que é a precariedade das condições de trabalho, buscar a alternativa de ter professores generalistas habilitados (supostamente) para lecionar qualquer conteúdo das grandes áreas.

Nossos protestos tiveram algum efeito, pois a Câmara dos Deputados aprovou um substitutivo ao projeto original que trouxe melhor solução para a questão dos currículos escolares. Do ponto de vista que interessa aqui, o mais significativo na nova redação do projeto é uma menção explícita à história e à geografia, ao lado da sociologia e da filosofia, como componentes curriculares obrigatórios da área de ciências humanas. Uma vitória parcial, mas ainda há indefinições e projetos em debate que demandam atenção.

No momento, está em curso outra iniciativa do MEC que merece acompanhamento cuidadoso. Trata-se da elaboração de proposta para a chamada Base Nacional Comum Curricular, que significa tentativa de colocar em prática orientações do Plano Nacional de Educação. Há cerca de um mês foi anunciada a criação de uma comissão de especialistas para elaborar um documento preliminar para a base nacional comum curricular, que deverá ser entregue ao Conselho Nacional de Educação em fevereiro de 2016. Fiquemos alertas, portanto, para participar desses debates e contribuir para o bom andamento das propostas. A ANPUH não foi convidada a indicar representantes, embora a portaria ministerial preveja uma comissão de 116 membros, mas podemos participar assim mesmo, enviando propostas e integrando os debates públicos (que estão prometidos nos documentos, esperamos que para valer). Difícil saber se essa iniciativa do MEC 
vai se efetivar, já que colocar 116 pessoas para trabalhar juntas é um desafio enorme, e dentro do próprio governo há posições divergentes. De qualquer modo, nosso papel é estar atentos e participar.

Por isso, não foi sem motivo que dedicamos à questão das propostas de reformulação dos currículos escolares a última jornada de debates da ANPUH, em maio deste ano, quando reunimos colegas experientes nesse campo para debater a situação. Nos trabalhos da Jornada ficou claro que temos algumas divergências em certos pontos, mas também ficou evidente a existência de um consenso básico em defesa das especificidades da disciplina e do conhecimento histórico.

Naquela Jornada levantamos uma questão crucial para o debate sobre a importância da história no ensino básico, que também implica o lugar da história de maneira mais ampla. Trata-se da pergunta clássica: para que serve a história? (que pode incluir a variante "a quem serve a história?") Essa pergunta já foi formulada inúmeras vezes e mereceu a atenção de figuras luminares da historiografia, como Marc Bloch, por exemplo. Seria ingênuo, portanto, pretender dizer algo de novo. Mas é relevante recolocar o questionamento clássico mais uma vez, neste momento em que parecem surgir dúvidas sobre o lugar da história nas escolas e em outros espaços públicos, e, também, em que muitos se contentam com registros de memória e a febre comemoriacionista para atender à curiosidade sobre o passado.

O deslocamento da história acadêmica para lugar social menos prestigiado é tendência visível em certos países, ao ponto de alguns autores falarem, 3.32 apropriadamente ou não, em crise da história. Na França, por exemplo, país em que a nossa disciplina assumiu lugar proeminente no mundo da cultura e no mundo acadêmico, o pessimismo parece ter tomado conta das oficinas de Clio. Entre as evidências citadas para demonstrar a suposta crise estão a queda na vendagem de livros, o desinteresse dos jovens em seguir a profissão e a falta de cargos universitários.

$\mathrm{Na}$ análise de François Hartog sobre o declínio do regime moderno de história, o tema da crise encontra fundamentação mais sofisticada. Segundo essa perspectiva, o regime moderno de historicidade entrou em crise por não haver mais um horizonte de expectativas à frente - nem revolução redentora, nem nação, nem o progresso. O conceito moderno de história, que surgiu na passagem entre os séculos XVIII e XIX com base na tensão entre espaço de experiência e horizonte de expectativa, quando a percepção de que um tempo em constante mudança e um futuro brilhante iluminavam o olhar sobre o passado, nos termos da bela análise de R. Koselleck, foi deslocado da posição dominante que vinha ocupando desde então. Como em anos recentes o futuro passou a ser visto não mais como promessa de um mundo melhor, mas, ao contrário, como ameaçador e potencialmente trágico, o regime moderno de historicidade vem sendo superado pelo presentismo. De acordo com essa análise, ao contrário da história, que perscruta a experiência humana no tempo com base no afastamento crítico e na preocupação de perceber mudanças, a febre comemoracionista e a onda memorialista, nutridas pelo presentismo, disseminam um olhar que sugere identificação e atemporalidade. Na inspirada imagem evocada por Hartog, a 
musa da História, Clio, está a ser superada por sua mãe, Mnemosine, a deusa da memória, que vem assumindo (ou reassumindo) o seu lugar de proeminência. Enfim, parece haver de fato algumas nuvens ameaçadoras no horizonte do nosso campo de saber e da nossa profissão, tanto aqui como alhures.

Por isso, reiterando, é necessário levantar questões que ajudem a pensar o nosso lugar na sociedade. Então, perguntemo-nos ainda uma vez: por que a história (por certo, a história acadêmica, crítica etc.)? Por que a sociedade e o Estado deveriam manter o lugar privilegiado que essa disciplina ocupa tradicionalmente? Ainda é justificável o investimento na história? Afinal, não estariam superados os contextos políticos que produziram o interesse pela história, em especial o impulso para construir identidades nacionais e fortalecer as organizações estatais correspondentes? Se o Estado nação que institucionalizou a história está em crise, também ela não estaria em vias de superação como campo de saber relevante? Se não há mais horizonte de expectativa e estamos condenados a um eterno presente e à memorialização nostálgica do passado, para que a história?

Como se trata de encontrar razões para que a sociedade continue acreditando na relevância da história, e nela investindo recursos públicos, notadamente nos campos da educação e da pesquisa, respostas espirituosas do tipo "a história serve para dar trabalho aos historiadores" não resolvem o problema. Também não é suficiente dizer que a história serve para atender à curiosidade sobre o passado, a dos próprios historiadores e a dos segmentos do público que se interessam. Isso é verdade e, de fato, é perfeitamente legítimo dedicar a vida a essa curiosidade, e ao prazer que a paixão da descoberta nos proporciona. No entanto, não parece motivo suficiente para que a sociedade financie o estudo e o trabalho de milhares de profissionais, e destine a esse campo do saber um lugar destacado no sistema escolar.

Creio que a defesa mais eficaz da história passa pela recuperação de argumentos clássicos, portanto, nada de surpresas. Mas, também, passa por recolocar velhos temas sob novos ângulos. Em grande medida, há que retomar alguns termos da discussão anterior sobre o lugar político da história, seu papel na formação de cidadãos e no debate sobre alternativas para o presente e o futuro.

Ressalve-se, mais uma vez: a referência é a um engajamento político da história orientado para a democracia, para o pluralismo. Pois a história tem servido também para justificar a opressão, a violência e o autoritarismo. Em tais situações, a propósito, o lugar dos historiadores é denunciar tais usos/ manipulações do conhecimento, tais formas de exploração política da história, para o que devemos lançar mão de instrumentos proporcionados pela própria história acadêmica, como o seu aparato crítico e o compromisso com a busca da verdade. No entanto, como os valores democráticos podem ser divulgados também por outras áreas do saber, é fundamental destacar o que seria específico à nossa disciplina.

A história não é magistra vitae, impossível acreditar ainda nessa fórmula. Muitos atores nada aprenderam com a experiência do passado e repetiram 
os mesmos erros. Porém, o conhecimento histórico pode contribuir para a formação de cidadãos críticos, ao oferecer-lhes oportunidade de analisar o seu lugar na experiência temporal e escolher caminhos de ação. A história ainda é indispensável para compreender o mundo e para fundamentar as decisões atuais, na medida em que coloca em perspectiva a experiência humana no tempo. Recuperando o que foi dito antes, como é possível a um cidadão formar sua opinião e valores políticos sem tomar como referência experiências passadas, mesmo que seja para recusá-las e buscar novas alternativas?

A história não é mais necessária para construir a identidade nacional, pelo menos não no sentido que esse projeto teve no século XIX. Mas ainda é útil ao esforço de entender o que somos e a conjecturar sobre o que desejamos ser. A pesquisa histórica segue importante para entender esse pedaço do Globo a que chamamos Brasil. Como ele se formou em conexão com outros espaços da América, da África, da Europa e da Ásia?

Como surgiu esta sociedade, que tem como grande marca um elevado padrão de desigualdade entre seus grupos componentes, uma característica estrutural que tem sido tão complicado superar? Como explicar essa cultura política, caracterizada, entre outros elementos, pela conciliação e acomodação de conflitos nos estratos da elite, o que contribui para tornar muito difícil romper com tradições arraigadas e democratizar o Estado? Como entender essa conformação étnica, simultaneamente miscigenada e elitista, que permite alguns níveis de aproximação horizontal ao mesmo tempo em que reafirma a 3.34 presença de um peculiar racismo?

Exatamente por isso, pela existência de tantos problemas ainda por enfrentar - e que se enraízam no passado - é que podemos olhar com menos pessimismo para as possibilidades da história e para o futuro. Nosso horizonte de expectativa não apresenta apenas nuvens espessas, ainda há o que buscar no futuro: uma sociedade menos desigual e mais democrática, que consiga alcançar desenvolvimento econômico e social sem destruir o meio ambiente; e que seja capaz de encontrar lugar neste mundo em constantes transformações com base em identidade plural e aberta às diferenças, mas, ao mesmo tempo referenciada em alguns traços comuns, indispensáveis para a convivência no mesmo espaço.

Verdade que essas expectativas não são tão ambiciosas como fazer uma revolução, ou construir uma nação. Difícil, nos dias atuais, deixar-se tocar ainda por utopias progressistas calcadas no otimismo iluminista. Porém, considerando a história brasileira, esse modesto horizonte de expectativas não é coisa de pouca monta, e pode alimentar os sonhos de qualquer um por muitos anos ainda. Desse modo, o conhecimento da história ainda pode contribuir para a projeção de um futuro melhor, de maneira que o regime moderno de historicidade não está superado totalmente, pelo menos nestas plagas.

Assim, caros e caras colegas, muitos são os lugares da história e dos historiadores. Atuemos nesses espaços, portanto, armados com a devida dedicação profissional, os necessários princípios éticos e o engajamento público, bem entendido. Seguimos ocupando lugares e funções sociais ainda 
muito relevantes. É gratificante perceber que, para além do grande prazer proporcionado pelo trabalho como historiador, a dedicação a esta profissão ainda tem importância social.

Trabalhemos, portanto, e enfrentemos os desafios com otimismo. E aproveitemos bem este lugar, o nosso XXVIII Simpósio Nacional de História, e os espaços e oportunidades que ele nos proporcionará. 